\title{
Review of Prescribing Practices for Intermittent Bolus Administration of Morphine
}

\author{
Keith Sine, Régis Vaillancourt, Elena Pascuet, Brenda Martelli, Christine Lamontagne, \\ Jacqueline Ellis, Elaine Wong, and Isabelle Gaboury
}

\begin{abstract}
Background: Several changes to medication safety practices were proposed in a pediatric hospital, including changing the period of patient observation after administration of opioids and limiting the availability of various concentrations of morphine in the patient care unit.
\end{abstract}

Objective: To document and review postoperative pain management for children on a surgical ward, specifically with regard to intermittent IV bolus administration of morphine, to help in assessing the impact of the proposed nursing practice changes.

Methods: Data were collected from records for narcotics and controlled drugs for the surgical ward over a 3-month period (April to June 2006). For each patient, data had been recorded for up to 7 consecutive days after surgery. A patient's data were included in the review if he or she had received at least 2 doses of morphine by IV bolus, except for the review of weight-based dosing pattern $(\mathrm{mg} / \mathrm{kg})$, for which all patients who had received at least one dose of IV morphine were included.

Results: Charts for 193 patients were audited. Of these, 163 patients (84.5\%) had recieved up to $0.1 \mathrm{mg} / \mathrm{kg}$ per dose, and 53 (27.5\%) had received only one dose of morphine. Among patients who received more than one dose, the median dose was $0.080 \mathrm{mg} / \mathrm{kg}$ on day 1 , with a decrease by day 5 to $0.065 \mathrm{mg} / \mathrm{kg}$. Most patients received morphine over the first 2 days after surgery. The median time elapsed between doses was $4.3 \mathrm{~h}$ on day 1 and $6.2 \mathrm{~h}$ on day 2 . Of the 1020 doses included in the analysis, most (801 [78.5\%]) were $4 \mathrm{mg}$ or less.

Conclusion: The intermittent administration of IV bolus doses of morphine at the study hospital followed common standards for the treatment of postoperative pain. Most doses were no more than $4 \mathrm{mg}$. On the basis of this information, only 2-mg vials of morphine are now stocked on the ward. The hospital's change in monitoring practices will increase the surveillance of patients receiving IV bolus doses of morphine.

Key words: morphine, medication safety, pediatrics

\section{Can J Hosp Pharm 2011;64(1):25-30}

\section{RÉSUMÉ}

Contexte : Plusieurs changements aux pratiques en matière de sécurité des médicaments ont été proposés dans un hôpital pour enfants, y compris des changements dans la période d'observation des patients après l'administration d'opioïdes et la restriction de la disponibilité de diverses concentrations de morphine dans l'unité de soins aux patients.

Objectif : Décrire et passer en revue la prise en charge postopératoire de la douleur chez les enfants dans un service chirurgical, plus particulièrement en ce qui a trait à l'administration i.v. intermittente de bolus de morphine, pour aider à évaluer l'incidence des changements de pratiques infirmières proposés.

Méthodes : Des données ont été tirées des registres de stupéfiants et de drogues contrôlées du service chirurgical sur une période de trois mois (avril à juin 2006). Les données ont été consignées pour chacun des patients jusqu'à sept jours consécutifs après l'intervention chirurgicale. Les données d'un patient étaient incluses dans l'analyse si ce patient avait reçu au moins deux doses de morphine en bolus i.v., sauf dans l'analyse des schémas posologiques en fonction du poids $(\mathrm{mg} / \mathrm{kg})$, auquel cas tous les patients qui avaient reçu au moins une dose de morphine par voie i.v. étaient inclus.

Résultats : Les dossiers médicaux de 193 patients ont été examinés. De ces patients, $163(84.5 \%)$ avaient reçu jusqu’à $0.1 \mathrm{mg} / \mathrm{kg}$ par dose; 53 avaient reçu une seule dose de morphine. Des patients qui avaient reçu plus d'une dose, la dose médiane était de $0,080 \mathrm{mg} / \mathrm{kg}$ le jour 1 , réduite à $0,065 \mathrm{mg} / \mathrm{kg}$ au jour 5 . La plupart des patients avaient reçu de la morphine durant les deux premiers jours suivant l'intervention. Lintervalle médian entre les doses était de 4,3 heures le jour 1 et de 6,2 heures le jour 2. La plupart des 1020 doses incluses dans l'analyse (801 [78.5\%]) n'excédaient pas $4 \mathrm{mg}$.

Conclusion : L'administration i.v. intermittente de bolus de morphine à cet hôpital était conforme aux normes courantes pour la prise en charge postopératoire de la douleur. La plupart des doses ne dépassaient pas $4 \mathrm{mg}$. D'après ces renseignements, seuls des flacons de $2 \mathrm{mg}$ de morphine sont maintenant stockés dans le service. Le changement dans les pratiques de suivi dans l'établissement intensifiera la surveillance des patients qui reçoivent des bolus i.v. de morphine.

Mots clés : morphine, sécurité des médicaments, pédiatrie

[Traduction par l'éditeur] 


\section{INTRODUCTION}

$\mathrm{O}^{\prime}$ pioid therapy, specifically morphine, is the gold standard for the treatment of postoperative pain. ${ }^{1}$ Morphine is the most common opioid used for postsurgical care in pediatric cases, ${ }^{2}$ and it is usually administered intravenously. For many postoperative patients, the IV route has the additional advantage of already being available, because of the access port used for administration of drugs during the surgery. It has been noted that pediatric patients will often deny the existence of pain if the only routes available for injection of pain medication are intramuscular or subcutaneous. ${ }^{1,3}$ In addition, absorption of drugs administered by either of these 2 routes may be unpredictable (e.g., because of poor perfusion or the presence of adipose tissue). Although the oral route may be an option for the treatment of acute postoperative pain, it is often contraindicated (e.g., because of nausea and vomiting), or absorption of oral drugs may be too slow or unpredictable.

In pediatrics, morphine given by the IV route is dosed by weight, unless the dose calculated in this way exceeds the maximum recommended adult dose. In the treatment of acute pain, initial IV bolus dosing may range from 0.05 to $0.2 \mathrm{mg} / \mathrm{kg}$ per dose, with the maximum dose not to exceed $15 \mathrm{mg}^{4.6}$ Dosing for postoperative pain is most often given as needed at an interval of every 2 to 4 h. ${ }^{4.5}$ As in adults, dosing of opioid narcotics must be individualized; however, in pediatric cases, other concerns such as changing body composition and kinetics as the child matures must be acknowledged and taken into account. ${ }^{7}$ These modifications result in a wide range of dosing regimens. In the treatment of most cases of postoperative pain, it is expected that the dosage of injectable opioid should be decreased with time and/or the interval between doses should be lengthened. Furthermore, if the patient has an active gastrointestinal tract with no contraindications to oral therapy, stepdown therapy from an injectable opioid to an oral formulation should be considered as clinical circumstances warrant. ${ }^{8}$ At the author' institution at the time of this study, monitoring guidelines required documentation of vital signs before and every $5 \mathrm{~min}$ for $15 \mathrm{~min}$ after the first IV bolus infusion of morphine (for a total of 4 sets of vital signs) and hourly monitoring of respiratory and heart rates for $4 \mathrm{~h}$. No monitoring was required for subsequent doses.

This article describes the results of a retrospective analysis of the use of IV bolus morphine on the surgical ward of the Children's Hospital of Eastern Ontario (CHEO). The purpose of the analysis was to document postoperative pain management practices for children on a surgical ward in terms of the intermittent IV bolus administration of morphine. Specific areas of interest were dose, interval between doses, doses per day, and weight-based dosing pattern $(\mathrm{mg} / \mathrm{kg})$. The project goal was to review the utilization of IV bolus morphine in the context of assessing the impact of proposed changes in medication safety practices. These practices included changing the period of patient observation after administration of opioids and limiting the availability of various concentrations of morphine in the patient care unit.

\section{METHODS}

The study hospital is a pediatric quaternary care teaching facility serving a large catchment area that includes eastern Ontario, western Quebec, and the Baffin region. In 2006, CHEO admitted 5977 patients, and 2247 patients were treated on the surgical ward. Surgery at CHEO includes specialties such as orthopedics, urology, gastroenterology, neurosurgery, cardiology, and general surgery. Patients undergoing surgical treatment range in age from newborn to 18 years.

Data for the study were obtained by reviewing records for narcotics and controlled drugs from the surgical ward. More specifically, the dose of drug administered and the time interval between doses were extracted from these records. Data were collected for a 3-month period, from April to June 2006. For each patient, data had been recorded for 7 consecutive days, starting from the initial IV bolus dose of morphine after surgery. A patient's data were included in the analysis if he or she had received at least 2 doses of morphine, except for the analysis of weight-based dosing pattern $(\mathrm{mg} / \mathrm{kg})$, for which all patients who had received at least one IV dose of morphine were included.

The data were analyzed quantitatively by means of descriptive statistics (median and range). The authors discussed ethics approval with the chair of the CHEO Research Ethics Board. Such approval was deemed unnecessary because the data were obtained from an administrative database.

\section{RESULTS}

A total of 193 consecutive patient records were audited for this investigation. Fifty-three patients $(27.5 \%)$ received a single dose of morphine, and the other $140(72.5 \%)$ received more than 1 dose. Among these patients, the highest number of doses was noted on day 1 . The number of doses decreased by day 2 and then remained relatively constant through day 5 (Table 1).

Among the patients who received more than one dose, the median dose on day 1 was $0.080 \mathrm{mg} / \mathrm{kg}$. Over time, the median dose remained relatively stable, dipping slowly by day 5 to $0.065 \mathrm{mg} / \mathrm{kg}$ (Figure 1). The number of patients receiving morphine decreased from day 1 to day 5 (Table 1). Of the entire study sample (193 patients), 163 (84.5\%) received up to $0.1 \mathrm{mg} / \mathrm{kg}$ per dose and $19(9.8 \%)$ received more than $0.1 \mathrm{mg} / \mathrm{kg}$ per dose; for 11 patients (5.7\%) body weight was not recorded and the weight-based dose could not be calculated.

During the first postoperative day, the median time elapsed between doses was $4.3 \mathrm{~h}$, and on day 2 the median time was 
Table 1. Daily Dose of Morphine Given by IV Bolus to Postsurgical Pediatric Patients Who Received at Least 2 Doses

\begin{tabular}{|c|c|c|c|c|}
\hline Postoperative Day* & No. of Patients & Median & Dose, mg (IQR) & Total No. of Doses \\
\hline 1 & $128+$ & 4.0 & $(3.0-6.0)$ & 557 \\
\hline 2 & 66 & 3.0 & $(1.0-4.0)$ & 193 \\
\hline 3 & 24 & 2.0 & $(1.0-4.0)$ & 66 \\
\hline 4 & 14 & 2.0 & $(1.0-4.3)$ & 39 \\
\hline 5 & 10 & 1.5 & $(1.0-5.0)$ & 24 \\
\hline
\end{tabular}

$\mathrm{IQR}=$ interquartile range.

*Data for postoperative days 6 and 7 were not included in this analysis, because of low numbers of patients still receiving morphine by IV bolus administration on these days ( 6 patients on postoperative day 6 and 2 patients on postoperative day 7). tFor one patient, the dose given on day 1 was missing, although the date and time of dosing were available.

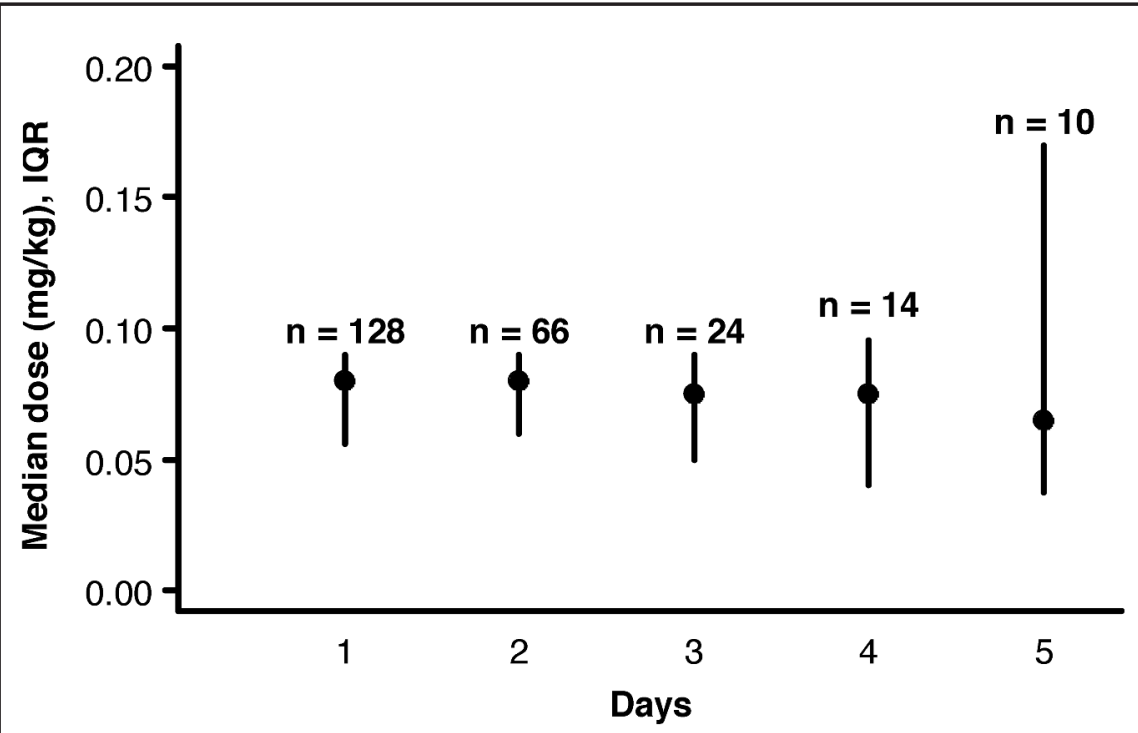

Figure 1. Median weight-based dose of morphine over the first 5 postoperative days. The number of patients for each day is indicated as the $n$ value. Of the original 193 patients, 53 received only one dose and were excluded from this analysis. For an additional 11 patients, body weight was missing, so weight-based dose could not be calculated. For 1 patient, time of dosing was not recorded for doses given on the first postoperative day, so the data were excluded from this analysis. Very few patients received morphine by IV bolus administration on postoperative days $6(n=6)$ and 7 $(n=2)$, so these days were not included in this analysis.

$6.2 \mathrm{~h}$ (Figure 2). The number of patients who received multiple doses of morphine daily decreased with time after surgery (Table 2, Figure 2).

In terms of dosing pattern, 801 (78.5\%) of the 1020 doses administered over the 3 -month period were $4 \mathrm{mg}$ or less. A total of 212 doses (20.8\%) were above $4 \mathrm{mg}$ but less than $10 \mathrm{mg}$ (and of these, doses of exactly $5 \mathrm{mg}$ accounted for 165 or $16.2 \%$ of the total). Only 7 doses $(0.7 \%)$ were greater than $10 \mathrm{mg}$.

\section{DISCUSSION}

The first 2 days are potentially the most painful in the postoperative period. Accordingly, it was unsurprising that doses of injectable morphine administered during the first 2 postoperative days accounted for the largest proportion of doses in the study reported here.

The dosing of morphine remained relatively constant over the first 4 days of data collection, with a median dose of 0.080 $\mathrm{mg} / \mathrm{kg}$. This value falls within the recommended range for use of morphine for acute postoperative pain in pediatrics (0.05 to $0.2 \mathrm{mg} / \mathrm{kg}){ }^{4-6} \mathrm{In}$ addition, this value is in close agreement with the dose of $0.08 \mathrm{mg} / \mathrm{kg}$ recommended by Kart and others ${ }^{9}$ in a review of the clinical use of morphine for treatment of acute pain in pediatric patients. In the present analysis, $84.5 \%$ of the patients $(163 / 193)$ received doses of $0.1 \mathrm{mg} / \mathrm{kg}$ or below, and 
Table 2. Use of Multiple Daily Doses of Morphine by IV Bolus

\begin{tabular}{|c|c|c|c|c|}
\hline \multirow[b]{2}{*}{$\begin{array}{l}\text { No. of Doses } \\
\text { per Day }\end{array}$} & \multicolumn{4}{|c|}{$\begin{array}{c}\text { Postoperative Day*; No. (\%) of Patients } \\
\text { Receiving Multiple Doses }\end{array}$} \\
\hline & Day $1(n=128)$ & Day $2(n=66)$ & Day $3(n=24)$ & Day $4(n=14)$ \\
\hline 1 & $6(5)$ & $20(30)$ & $7(29)$ & $4(29)$ \\
\hline 2 & $24(19)$ & $11(17)$ & $8(33)$ & $4(29)$ \\
\hline 3 & $26(20)$ & $14(21)$ & 1 (4) & $2(14)$ \\
\hline 4 & $13(10)$ & $8(12)$ & $3(12)$ & 1 (7) \\
\hline 5 & $20(16)$ & $8(12)$ & $2(8)$ & $2(14)$ \\
\hline
\end{tabular}

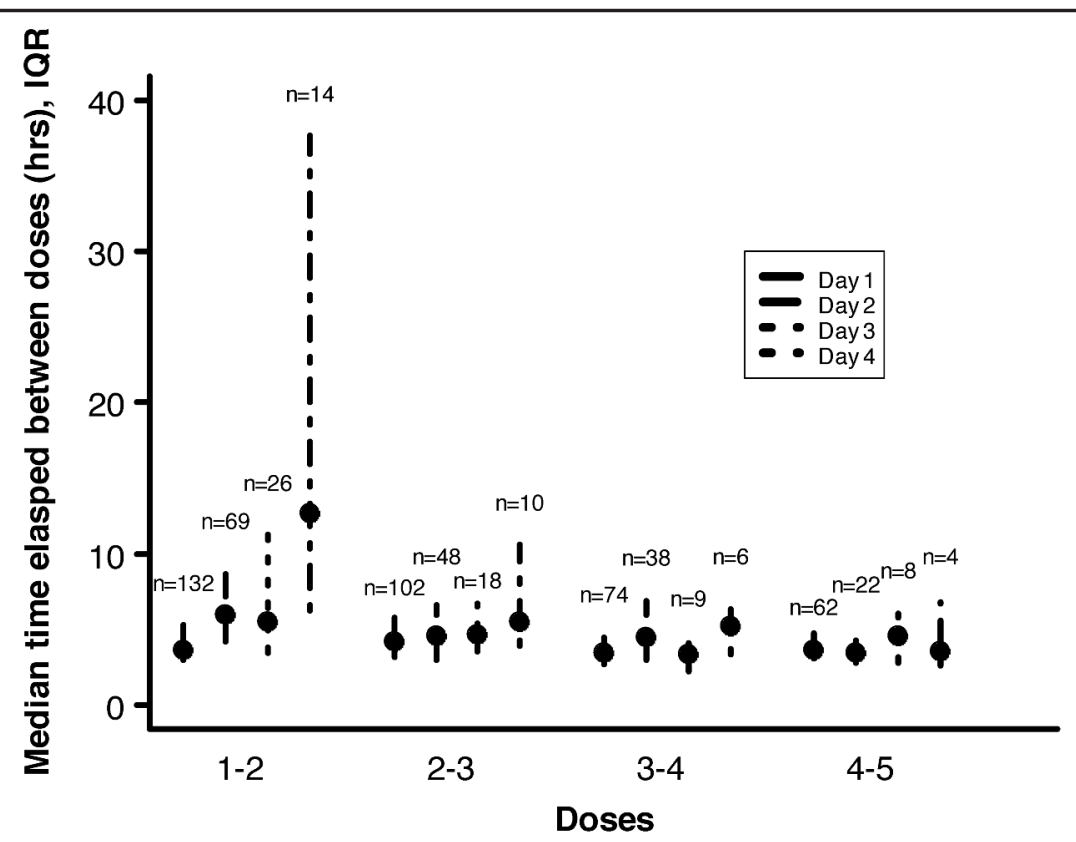

Figure 2. Time elapsed between pairs of doses over the first 4 postoperative days. Data are expressed as medians and interquartile ranges (IQRs). On the horizontal axis, "1-2" refers to the interval between the first and second doses, " $2-3$ " refers to the interval between the second and third doses, and so on. The number of patients for each data point is indicated as the $n$ value. If the time between 2 consecutive doses was more than $24 \mathrm{~h}$, the second dose was registered on the next day. Data for time elapsed were not formally analyzed for postoperative days 5 through 7. By the fifth postoperative day, only 10 patients were still receiving morphine: 4 patients received a single dose on postoperative day 5, 2 patients received 3 doses, 3 patients received 6 doses, and 1 patient did not receive any morphine that day. By the sixth postoperative day, only 6 patients were still receiving morphine; these patients received 1 (3 patients), 3, 4, and 6 doses, respectively. By the seventh postoperative day, only 2 patients were receiving morphine ( 1 and 4 doses, respectively).

doses for a further $5.7 \%$ of patients $(11 / 193)$ could not be analyzed because the patient's weight had not been recorded. As a safety measure for postoperative patients not previously receiving a narcotic, it is suggested that nursing staff consider dividing the patient's weight by a factor of 10 to get a rough estimate of the total dose that would be equivalent to a weight-based dose of $0.1 \mathrm{mg} / \mathrm{kg}$ (e.g., a patient weighing $20 \mathrm{~kg}$ would be expected to receive a total dose of $2 \mathrm{mg}$ ). This quick mathematical check would help to ensure that initial dosing falls within the median dosing found in this analysis. Over the course of therapy (and considering only patients who received multiple doses and for whom body weight was available), the number of patients receiving the drug by the parenteral route decreased with time after surgery: 128 patients received morphine on day 1 , and only $66(51.6 \%)$ of these required the drug on day 2 . By day 3, 104 $(81.3 \%)$ of the 128 patients were no longer receiving IV bolus 
morphine, and only 24 were still receiving the drug. This rapid decrease in the use of injectable morphine agrees well with previous studies, such as that of Jylli and others, ${ }^{10}$ who found that $83.4 \%$ of pediatric patients had been taken off patientcontrolled morphine therapy by 3 days after surgery. Finally, the data on median dosage did not indicate any development of analgesic tolerance over the initial 5-day period. The lack of analgesic tolerance and the dosage interval over the study period suggest that patients' pain was adequately controlled.

The use of continuous IV administration or patientcontrolled analgesia should be considered for pediatric patients, given the large number of patients in this study who were still receiving morphine by intermittent IV bolus administration on the second postoperative day. Also of importance is the practice of using "as needed" opioid analgesia instead of scheduled postoperative doses. It is probable that most patients in this analysis received morphine on an as-needed basis. It is known that postsurgical pain control on an as-needed basis is more likely to be associated with an increase in the overall amount of opioid used, as well as subjecting the patient to more stress and pain, relative to scheduled administration of analgesia. ${ }^{6,9}$ As such, as-needed morphine therapy may be a poorer option than continuous IV morphine during the early postsurgical period.

Similar to continuous IV infusions of opioid after surgery, the use of patient-controlled analgesia is more likely to result in less opioid usage and provide better pain relief. ${ }^{11}$ Previous studies have noted that patients as young as 6 years were capable of using patient-controlled analgesia. ${ }^{11} \mathrm{~A}$ final therapeutic point to consider is the negative effect that postoperative pain may have in terms of increasing morbidity during the hospital stay. ${ }^{12}$ Analyzing the change from a system standpoint, administration of morphine by continuous IV infusion or patientcontrolled analgesia would shift the preparation of product to standardized concentrations in a centralized location (the pharmacy), thus decreasing the requirement for nurses to calculate and prepare individual doses in the patient care area; it would also allow use of technology (i.e., "smart pumps") for weight-based dose verification and limits. ${ }^{13}$ Furthermore, patient-controlled analgesia or continuous IV administration would require double-checking of pump programming (initial settings and subsequent changes), which is an additional safety check. In addition, the patient's oxygen saturation would be monitored continuously for the duration of the therapy.

The time elapsed between doses of morphine during the first day of therapy $(4.3 \mathrm{~h}$ ) agreed well with information reported by Duedahl and Hansen, ${ }^{2}$ who showed an elapsed time of up to $3.5 \mathrm{~h}$. In addition, this administration interval remained relatively stable over the initial 4-day postoperative period. Of note, the number of doses received during any given day decreased, which probably indicates that the pain was controlled and the patients either stopped the analgesia completely or, more likely, stepped down to oral therapy (e.g., opioid, acetaminophen) or rectal therapy (e.g., acetaminophen). However, it should be noted, as stated earlier, that the kinetics of morphine for acute postoperative pain in pediatric patients allow for a dosing interval of 2 to $4 \mathrm{~h}$; in this study, the median dosage interval on day 1 was $4.3 \mathrm{~h}$. This value suggests that in the early postoperative period, it may be appropriate to order continuous administration of morphine (e.g., by IV infusion), with as-needed doses for breakthrough pain. Such a change would probably decrease the workload for nurses in terms of preparing and administering medications.

In terms of nursing workload, if intermittent IV bolus administration continues to be the norm, the proposed changes in monitoring would shift the intensity of monitoring from the first dose and would extend monitoring to subsequent doses for which formal monitoring has not been conducted. At the time of this analysis, the morphine monitoring in place was restricted to vital signs every $5 \mathrm{~min}$ for $15 \mathrm{~min}$ after the initial dose and monitoring of respiration and heart rates every hour for $4 \mathrm{~h}$ after the first dose, with no further monitoring for subsequent doses.

Interestingly, $78.5 \%$ of the doses for intermittent IV morphine fell at or below $4 \mathrm{mg}$. Morphine is considered a high-alert drug that was included in the first list of high-alert drugs published by the Institute for Safe Medication Practices (ISMP_US) 20 years ago. ${ }^{14}$ In the most recent list of high-alert medications, published by ISMP in 2008, opioids are still listed. ${ }^{15}$ The current analysis supports the use of 2 -mg vials on the surgical ward at CHEO, which would decrease the risk of overdose. In addition, doses falling between 4 and $10 \mathrm{mg}$ accounted for the majority of additional dosing (20.8\%), with 5-mg dosing accounting for $77.8 \%$ of the doses in this interval. This information may facilitate the elimination of $10-\mathrm{mg}$ vials of morphine from the surgical unit.

This study had a number of limitations. The information for analysis was obtained from the records for narcotic and controlled drugs only. However, these records are not always accurate in terms of the time of administration or the dose given. ${ }^{16}$ Other limitations were the lack of information about confounding variables such as adjunctive medications (e.g., acetaminophen or nonsteroidal anti-inflammatory drugs, which would reduce the need for opioids), ${ }^{2,11,17,18}$ additional nonpharmacological therapies, and the presence or absence of family members. ${ }^{19}$

Points for future study that were not analyzed in the present study include comparison of patient-controlled analgesia and continuous IV infusion of morphine with IV bolus morphine in terms of overall dose and duration of therapy, pain scores, and use of adjunctive medications in the treatment of pain. In addition, the present study grouped all surgeries together, and differences in dosing morphine, even if appropriate overall, could not be attributed to the type of surgery. As such, an analysis by type of surgery would be of interest. 


\section{CONCLUSIONS}

The administration of intermittent bolus doses of morphine at CHEO appears to follow what is known about morphine kinetics and the treatment of postoperative pain. The dosing of morphine, in terms of amount given, dosing intervals, and duration of therapy, does not appear excessive. However, the large number of patients still receiving morphine by IV administration on postoperative day 2 does suggest that the use of intermittent bolus dosing should be reviewed from the viewpoint of patient analgesia and nursing workload. In addition, the most common dose, up to $4 \mathrm{mg}$, appears to account for the majority of doses given to our patient population on the surgical ward. This information has led to a change in stocking practices on the surgical ward at the study hospital, such that only 2-mg vials of morphine are now stocked.

\section{References}

1. Starship children's health clinical guideline: morphine administration. Auckland (NZ): Starship Children's Health; [reviewed 2008 Apr; cited 2009 Jan]. Available from: www.starship.org.nz/assets/Uploads/ Starship-Hospital-Content/Health-Professionals/Clinical-Guidelines/ Morphine-Administration.pdf

2. Duedahl TH, Hansen EH. A qualitative systematic review of morphine treatment in children with postoperative pain. Paediatr Anaesth 2007; 17(8):756-774.

3. Maunuksela EL, Korpela R, Olkkola KT. Double-blind, multiple-dose comparison of buprenorphine and morphine in postoperative pain of children. Br J Anaesth 1988;60(1):48-55.

4. Phelps S, Hak E, Cril C, editors. Pediatric injectable drugs. 8th ed. Rockville (MD): American Society of Health-System Pharmacists Inc; 2007.

5. Drugdex evaluations: morphine. In: Micromedex. Evanston (IL): Thomson Reuters (Healthcare) Inc; [cited 2009 Jan 8]. Available from: https://www.thomsonhc.com/hcs/librarian/PFDefaultActionId/ pf.LoginAction. Subscription required to access content.

6. Baños JE, Barajas C, Martin ML, Hansen E, Cos MÁ, Bosch F, et al. A survey of postoperative pain treatment in children of 3-14 years. Eur J Pain 1999;3(3):275-283.

7. Kart T, Christrup LL, Rasmussen M. Recommended use of morphine in neonates, infants and children based on a literature review: part 1 pharmacokinetics. Paediatr Anaesth 1997;7(1):5-11.

8. American Academy of Pediatrics, Committee on Psychosocial Aspects of Child and Family Health; American Pain Society, Task Force on Pain in Infants, Children, and Adolescents. The assessment and management of acute pain in infants, children, and adolescents. Pediatrics 2001; 108(3):793-797.

9. Kart T, Christrup LL, Rasmussen M. Recommended use of morphine in neonates, infants and children based on a literature review: part 2 clinical use. Paediatr Anaesth 1997;7(2):93-101.

10. Jylli L, Lundeburg J, Langius-Eklöf A, Olsson GL. Comparison of the analgesic efficacy of ketobemidone and morphine for management of postoperative pain in children: a randomized, controlled study. Acta Anaesthesiol Scand 2004;48(10):1256-1259.
11. Berde C, Sethna N. Analgesics for the treatment of pain in children. $N$ Engl J Med 2002;347(14):1094-1103.

12. Rahman M, Beattie J. Managing post-operative pain. Pharm J 2005; $275: 145-148$

13. Colquhoun M, Koczmara C. Medication safety alerts. Narcotic (opioid) safety: an ISMP Canada medication safety support service project. Can J Hosp Pharm 2005;58(3):162-164.

14. Davis NM, Cohen MR. Today's poisons: how to keep them from killing your patients. Nursing 1989;19(1):49-51.

15. ISMP's list of high alert medications. Horsham (PA): Institute for Safe Medication Practices; 2008 [cited 2009 Jan 13]. Available from: www.ismp.org/tools/highalertmedications.pdf

16. Colquhoun M, Koczmara C, Greenall J. Implementing system safeguards to prevent error-induced injury with opiods (narcotics): an ISMP Canada collaborative. Healthc Q 2006;9 Spec No.:36-42.

17. Hernández-Palazón J, Tortosa JA, Martínez-Lage JF, Pérez-Flores D. Intravenous administration of propacetamol reduces morphine consumption after spinal fusion surgery. Anesth Analg 2001;92(6):1473-1476.

18. Remy C, Marret E, Bonnet F. Effects of acetaminophen on morphine side-effects and consumption after major surgery: meta-analysis of randomized controlled trials. Br J Anaesth 2005;94(4):505-513.

19. Zempsky W. Optimizing the management of peripheral venous access pain in children: evidence, impact, and implementation. Pediatrics 2008;122 Suppl 3:S121-S124.

Keith Sine, BSc(Pharm), PharmD, is with the Department of Pharmacy, Children's Hospital of Eastern Ontario, Ottawa, Ontario. At the time of the study, he was a PharmD student with the University of Toronto.

Régis Vaillancourt, OMM, CD, BPharm, PharmD, FCSHP, is with the Department of Pharmacy, Children's Hospital of Eastern Ontario, Ottawa, Ontario. He is also an Associate Editor with the CJHP.

Elena Pascuet, BSc, MSc, is with the Department of Pharmacy, Children's Hospital of Eastern Ontario, Ottawa, Ontario.

Brenda Martelli, RN(EC), OCT, BSCN, BEd, MEd, is with Integrated Pain Services and Complex Care, Children's Hospital of Eastern Ontario, Ottawa, Ontario.

Christine Lamontagne, MDCM, FRCPC, is with the Department of Anesthesia, Children's Hospital of Eastern Ontario, Ottawa, Ontario.

Jacqueline Ellis, RN, PhD, is with the Nursing Department, Children's Hospital of Eastern Ontario, Ottawa, Ontario.

Elaine Wong, BPharm, is with the Department of Pharmacy, Children's Hospital of Eastern Ontario, Ottawa, Ontario.

Isabelle Gaboury, PhD, is with the CHEO Research Institute, Ottawa, Ontario.

\section{Address correspondence to:}

Dr Régis Vaillancourt

Pharmacy

Children's Hospital of Eastern Ontario

401 Smyth Road

Ottawa ON K1H 8L1

e-mail: rvaillancourt@cheo.on.ca 